\title{
DA ORIENTAÇÃO PROFISSIONAL A RE-ORIENTAÇÃO \\ PROFISSIONAL: REFLEXÕES ACERCA DA ATUAÇÃO DO PSICÓLOGO FRENTE AO ATUAL CENÁRIO DE MUDANÇAS PROFISSIONAIS
}

\author{
FROM VOCATIONAL GUIDANCE TO VOCATIONAL REORIENTATION: REFLECTIONS ON THE \\ ROLE OF PSYCHOLOGISTS IN FACE OF CURRENT PROFESSIONAL CHANGES
}

${ }^{1}$ Acadêmicas do curso de Psicologia da UNIPAR

${ }^{2}$ Docente do curso de Psicologia da UNIPAR
Aline dos Santos Fabris ${ }^{1}$

Bruna Cardoso Zinhani ${ }^{1}$

Bruna Morgana Giraldi Barão ${ }^{1}$

Gabriella Marcondes do Amaral ${ }^{1}$

Raquel Carvalho Lisboa ${ }^{1}$

Maria Adelaide Pessini²
FABRIS, A. dos S.; ZINHANI, B. C.; BARÃO, B. M. G.; AMARAL, G. M. do; LISBOA, R. C.; PESSINI, M. A. Da orientação profissional a re-orientação profissional: reflexões acerca da atuação do psicólogo frente ao atual cenário de mudanças profissionais. Akrópolis Umuarama, v. 25, n. 1, p. 13-24, jan./jun. 2017.

DOI: 10.25110/akropolis.v25i1.6670

Resumo: O presente artigo pretende ressaltar aspectos acerca da atuação do psicólogo enquanto orientador e reorientador profissional, e o quão amplo é este processo, tendo em vista seus ricos subsídios teóricos e práticos para o cenário contemporâneo, que tem apresentado uma vasta demanda desta prática em diversas circunstâncias perpassadas pelos sujeitos. Na busca de um trabalho preventivo e simultaneamente que promova qualidade de vida, apresentamos as possibilidades em que se pode servir da reorientação; um breve histórico desta prática no Brasil e as principais teorias psicológicas que dão suporte à orientação profissional. Para atingir os objetivos desta pesquisa foi realizado um cauteloso garimpo das revisões bibliográficas. Com o estudo, pode-se concluir que a práxis do psicólogo na orientação profissional ou na re-orientação profissional requer conhecimentos teórico, metodológico e das singularidades de cada sujeito (orientando ou re-orientando) e do contexto onde os mesmos estão inseridos.

Palavras-chave: Orientação; Possibilidades; Qualidade de vida; Reorientação.

ABSTRACT: This paper aims to emphasize aspects related to the role of psychologists as a guiding and reorienting professional, and the amplitude of this process, given its rich theoretical and practical subsidies for the contemporary scenario, which has presented a broad demand of this practice in different circumstances experienced by the subjects. In the search for a preventive work and simultaneously to promote quality of life, this study presents the possibilities that can be used by reorientation; a brief history of this practice in Brazil and the major psychological theories that support vocational guidance. In order to achieve the purposes of this study, a thorough literature review was performed. Therefore, it can be conclude that the psychologist practice in professional guidance or professional reorientation requires both theoretical and methodological knowledge, as well as knowledge on the singularities of each subject (being guided or redirected) and of the context 
where they are inserted in.

KeYwords: Orientation; Possibilities; Quality of life; Reorientation.

\section{INTRODUÇÃO}

O tempo de mudanças vivido pela sociedade mundial, tem sido de grande valor técnico científico e econômico, porém tem implicado em problemas de desenvolvimento para o ser humano, que embora seja protagonista neste processo, não tem a capacidade de acompanhar psicologicamente o ritmo das transformações, principalmente no que diz respeito à escolha e/ ou mudança no campo do trabalho. Independente da relação de causa e consequência entre desemprego e tecnologia, as alterações tem sido consideráveis.

Neste cenário, refletir sobre a atuação do psicólogo na reorientação profissional e buscar conhecimentos que subsidiem essa prática adquire importância sem precedentes, a partir do momento em que proporciona um conhecimento sobre o desenvolvimento histórico da orientação profissional, sobre os princípios teóricos que norteiam essa prática e sobre os contextos em que a reorientação profissional é possível.

A orientação profissional acompanhou as transformações do mundo do trabalho concomitantemente às mudanças de sua própria prática exigidas por cada contexto histórico. Além disso, a orientação profissional utiliza demasiadas abordagens teóricas como uma das ferramentas primordiais no trabalho com o indivíduo/orientando. Através das perspectivas psicológicas é possível auxiliar o orientando, suprindo suas necessidades conforme as práticas científicas que permeiam determinadas teorias. Com isso, faz-se necessário o conhecimento de tais abordagens, as quais são imprescindíveis na realização de um trabalho eficiente.

Diante disso, a orientação profissional vai além, com os estudos antropológicos, históricos e filosóficos unidos a psicologia, sendo possível trabalhar com conteúdos bem mais profundos da subjetividade humana, pois não se restringe só a informação profissional do sujeito, como também pode ser comparada à clínica. Porém, em hipótese alguma como intervenção psicoterápica, ou seja, a psicologia tem como objetivo promover equilíbrio do indivíduo, através da prevenção e promoção da saúde. Portanto, a orientação profissional estabelece um espaço lisonjeado, pois atua com as escolhas do sujeito, isto é, em seu alicerce. Assim, essa atuação torna-se um trabalho de prevenção, aderido a psicoprofilaxia, almejando o bem-estar geral do sujeito, pois, esta psicoprofilaxia pode ser compreendida como toda atividade que, através de um esboço de análise psicológica e por meio do manejo de recursos e técnicas psicológicas, procure promover o desenvolvimento das potencialidades do ser humano, seu amadurecimento como pessoa e, finalmente, sua felicidade.

Logo, destacaremos no decorrer do artigo algumas teorias que subsidiam as práticas da orientação profissional, bem como os autores que as compõem, denotando suas percepções acerca do sujeito e do ambiente que o permeia, constituindo fatores que influenciam no processo de escolha e decisão. Sendo assim, cada abordagem visualiza e decodifica os variados contextos de maneiras diferentes, mas cada uma contribuindo significativamente para obtenção de resultados positivos. Portanto, ressaltamos respectivamente a Psicanálise; Análise do Comportamento; Sócio-cognitiva e a Fenomenológico-Existencial.

\section{UMA BREVE HISTÓRIA DA ORIENTAÇÃO PROFISSIONAL NO BRASIL}

Os primeiros indícios da Orientação Profissional no Brasil aparecem no início do século XX, conforme é exposto por Abade (2005), tendo como acontecimento relevante a seleção de alunos para o curso de Mecânica Prática no Liceu de Artes e Ofícios de São Paulo em 1924, neste momento a Orientação Profissional era estritamente psicométrica.Concordando com Brown \& Brooks (1996); Carvalho (1995); Super\&Bohn Junior (1970/1976) apud Sparta (2003), durante as décadas de 1920 e 1930 a prática da Orientação Profissional passa a ser influenciada pela Psicologia Diferencial e pela Psicometria, abordando e desenvolvendo testes de inteligência, aptidões, habilidades, interesses e personalidade.

A Orientação Profissional passou a ser um processo fortemente diretivo, em que o orientador tinha como objetivos fazer diagnósticos e prognósticos do orientando e, com base nesses procedimentos, indicar ao mesmo profissões ou ocupações apropriadas. (SPARTA, 2003, p. 2). 
É possível compreender que este método adotado pela Orientação Profissional, preocupava-se especificamente com ajustamento, em adequar as habilidades, aptidões, características pessoais à determinadas atividades e profissões, isto é, o homem certo no lugar certo, pode ser assinalado como Teoria do Traço e Fator (SPARTA, 2003).

Em 1947 foi criado o Instituto de Seleção e Orientação Profissional (ISOP) da Fundação Getúlio Vargas, objetivando promover o ajustamento entre as aptidões dos trabalhadores e os requisitos exigidos em cada profissão. Segundo Antunes (1991) apud Abade (2005) neste período a Orientação Profissional estava direcionada a racionalização e organização do trabalho visando obter aumento da produtividade. Visto que, os testes vocacionais visavam a direcionar os jovens para uma escolha relacionada às suas capacidades, no entanto, sem considerar características subjetivas dos sujeitos (ABADE, 2005).

Os trabalhos brasileiros ligados à temática da Orientação Profissional, a partir de 1971 sofreram grande influência de Bohoslavsky e suas publicações sobre a estratégia clínica em orientação vocacional, segundo exposto por Abade (2005). No entanto, durante a década de 70 tendo em vista a instauração da ditadura militar no Brasil, houve uma considerável diminuição das publicações referentes à Orientação Profissional.

Assim como a Psicologia na década de 80 aprimora e redefine suas práticas, a Orientação Profissional também apresenta considerável desenvolvimento. Neste momento o Instituto de Seleção e Orientação Profissional (ISOP) se transforma no Instituto Superior de Estudos e Pesquisas Psicossociais. A partir dos anos 80 a escolha profissional passa a ser considerada uma perspectiva multidisciplinar, a profissão e o indivíduo tendem a um caráter dinâmico (ABADE, 2005).

No início dos anos 90 houve um relevante aumento das publicações sobre Orientação Profissional. Em 1993 é criada a Associação Brasileira de Orientação Profissional (ABOP), sendo este evento um marco histórico de grande importância para a Orientação Profissional no Brasil. A ABOP surge oferecendo suporte ao orientador profissional, e aos vários aspectos relacionados a esse ramo de atividade.

Melo-Silva (2007), considera a Associação Brasileira de Orientação Profissional
(ABOP) como uma comunidade civil sem intenção lucrativa que reúne Orientadores Profissionais do Brasil. Tendo em vista construir de forma compartilhada atividades que envolvem o desenvolvimento da Orientação Profissional (OP) em todo país, ampliando e desenvolvendo atividades técnicas e científicas envolvendo psicólogos e profissionais afins.

Além de congregar pesquisadores e profissionais, cabe às Associações Nacionais e Internacionais, neste domínio, atuarem firmemente com o propósito de estabelecer normas éticas, critérios de competência requeridos dos orientadores profissionais, qualidade dos serviços e das pesquisas, definição de políticas públicas de acesso democrático à Orientação Profissional e à Educação de qualidade. (MELO-SILVA, 2007, p. 1)

Conforme Melo-Silva (2007), desde seu início em 1993, a ABOP, atuou no desenvolvimento e na viabilização de diversos eventos que contribuíram para o fortalecimento e a ampliação do conhecimento científico e prático a respeito da Orientação Profissional no Brasil. Em 1997 a ABOP lançou a Revista Brasileira de Orientação Profissional, esta revista tem teor científico, sendo a única no domínio da Orientação Profissional no Brasil, abordando publicações a nível nacional, mas alcançando também o campo internacional, com a finalidade de conceber e propagar a ciência, produzindo reflexões sobre as demasiadas possibilidades da O.P. na contemporaneidade. Proporcionando um ambiente que aceita produções originais conexas a O. P. "que se enquadrem nas seguintes categorias: relatos de pesquisas, estudos teóricos, revisões críticas da literatura, comunicações breves sobre pesquisas, relatos de experiência profissional, ensaios, notas, técnicas, resenhas" (MELO-SILVA, 2007, p. 6).

\section{TEORIAS PSICOLÓGICAS QUE SUBSIDIAM A PRÁTICA DA ORIENTAÇÃO PROFISSIO- NAL E DA RE-ORIENTAÇÃO PROFISSIONAL}

A partir das concepções históricas da O. P., torna-se possível definir a relevância das abordagens teóricas enquanto instrumentos indispensáveis ao orientador. Pois é por meio dessa base, denominada abordagem psicológica, que o profissional terá capacidade de analisar o sujeito, suas experiências passadas, suas cau- 
salidades, suas possibilidades e seu contexto, ou seja, todo seu conjunto bio-psico-social.

No entanto, cada profissional utiliza de uma teoria específica para auxiliá-lo no processo de orientação ou de re-orientçaão. Com isso, faz-se necessário o conhecimento das diversas abordagens existentes e consequentemente a aquisição de tal suporte, o qual é imprescindível para as práticas interventivas. Sendo assim, destacamos algumas teorias para o conhecimento prévio do leitor.

$\mathrm{Na}$ perspectiva psicanalítica foram muitos os representantes que muito contribuíram, no entanto, segundo Erlich, Castro e Soares (2000), Bohoslavsky, considerado um pesquisador expoente no campo da orientação vocacional, apresenta características relacionadas à adolescência e escolha profissional. Baseia-se no "sentido" humano, ou seja, na maneira como o homem atribui um significado ao trabalho, tornando-o algo transcendente a uma necessidade biológica; assim como nas palavras do próprio autor "supõe-se que as pessoas fazem alguma coisa 'por' alguma coisa e que fazem 'para' alguma coisa, entretanto, esta 'coisa' não está bem definida" (BOHOSLAVSKY, 1998, p. 41 apud EHRLICH, CASTRO e SOARES, 2000, p. 68).

Bohoslavsky também traz críticas sobre o homem ser enquadrado nos padrões que the são cabíveis e ao conceito liberal de liberdade de escolha, pois isto o torna sem razão de ser e ignora as historicidades e contextos individuais. Além disso, elucida que as pessoas têm a capacidade de escolher o seu futuro e definirem "quem ser", "quem não ser" e o "quê fazer". Portanto, há uma "personalidade" escolhendo, onde é apresentado o "princípio Freudiano que define as escolhas ocupacionais como resultado de um processo de sublimação de instintos" (EHRLI$\mathrm{CH}$, CASTRO e SOARES, 2000, p. 71).

Porém, esse processo exige perdas, pois o jovem estará deixando seu papel infantil para adquirir maturidade, perdendo a oportunidade de ser outro profissional, de viver outras possibilidades, perpassando incessantemente por sentimentos de angústia, medo, dúvidas e inquietações, convivendo com um conflito dentro de si mesmo, à procura de quem almeja ser (EHRLICH, CASTRO e SOARES, 2000).

Conforme as autoras Moura e Silveira (2002), na perspectiva da Análise do Comportamento, esse caminho pelo qual direciona os profissionais no momento de atuação, traz ba- ses para que o orientando possa, por meio de seu comportamento, encontrar um meio de fazer suas próprias escolhas, sem demais interferências, pois é nesse momento de escolher que as autoras supracitadas mencionam o behaviorista Skinner, que entende o comportamento de decidir como algo que pode ser moldado por diversos estímulos, os quais são muitas vezes ocasionados pelo próprio sujeito.

Um dos entraves da Análise do Comportamento é que essa perspectiva não objetiva a prática em O. P. como único meio de ação, o que permite que alguns analistas rejeitem o trabalho de atender o adolescente em sua problemática. Tal circunstância pode ser efeito de um modelo tradicionalista, a Orientação Vocacional, que pode ter um impacto espontâneo nos profissionais devido sua conotação. É por essa razão que o conceito de Análise entende que o indivíduo tem sua vocação construída através de seu meio social, cultural e pessoal, pois esses elementos perpassam sua história influenciando sob suas habilidades e interesses, que devem ser adaptadas de acordo com o ambiente em que vive (MOURA e SILVEIRA, 2002).

O comportamento verbal também tem um papel significativo no momento da O. P., pois, é por meio dele que o orientador será capaz de:

1) identificar pensamentos e sentimentos relativos a escolha profissional; 2) interpretar como os contextos passado e presente do adolescente interferem na tomada de decisão; 3) identificar (para, posteriormente alterar) regras mantenham relações impróprias ou distorcidas com contingências reais que se refiram à escolha profissional (MOURA e SILVEIRA, 2002, p. 8).

Dessa forma, o analista do comportamento obtém subsídios para uma ação posterior, podendo adequar e discutir algumas regras de acordo com o desenvolvimento do processo, garantindo resultados essenciais no processo individual de escolha, surtindo efeitos positivos sobre o indivíduo.

De acordo com Teixeira (2008), a perspectiva sócio-cognitiva prioriza o mundo e a responsabilidade do indivíduo, como meios que o impulsionem a atuar e mudar. Isso ocorre por meio de um processo denominado "autorregulatório", em que a pessoa constituirá suas próprias regras de funcionamento por meio da aprendizagem, consoante aos três fatores imprescindí- 
veis: indivíduo, ocasião e comportamento.

Portanto, o sujeito é compreendido como ser proativo em que suas ações são subsidiadas por seus objetivos particulares, além de executar uma avaliação de si mesmo, refletir e perceber o mundo através de suas crenças, as quais são constituídas a partir "[...] das experiências, das emoções, da aprendizagem por modelagem, e da persuasão verbal" (TEIXEIRA, 2008, p.12).

Por conseguinte, a perspectiva sócio-cognitiva alinhada ao domínio vocacional, concebida por Lent e Cols. (1994) apud Teixeira (2008), distingue-se em três modelos, sendo eles: o desenvolvimento dos interesses, as escolhas e o desempenho. Ambos os modelos contém "variáveis de natureza pessoal (e.g., sexo, raça, saúde) e situacional (e. g., família, escola, cultura)" (TEIXEIRA, 2008, p.12), as quais são significadas a partir da relação do sujeito com seu contexto. Além disso, abarca expectativas resultantes das experiências sociais e emocionais, que influenciam nos interesses e nas escolhas do indivíduo, propiciando novas experiências que culmina o autoconhecimento e a competência, ou seja,

De acordo com o modelo que explica o desempenho, a realização de uma tarefa resulta da interacção entre a capacidade, a crença de eficácia, as expectativas de resultados e os objectivos, e associa sempre procedimentos de avaliação. (TEIXEIRA, 2008, p. 13).

Segundo Erlich, Castro e Soares (2000), na perspectiva fenomenológico existencial Sartre refere-se à personalidade e o projeto de ser. Para este autor "a existência precede a essência", isso significa que o homem existe, encontra-se inserido no mundo e cercado por tudo o que nele há, mas que nenhum desses fatores determinará se ele será rico ou pobre, tímido ou extrovertido, professor ou empresário, ou seja, este indivíduo é livre para fazer suas próprias escolhas, independente dos fatores que o cercam. Livre porque está em suas mãos escolher ser este ou aquele, e fazer isto ou aquilo, sendo assim, ele próprio vai se definir através das condições de possibilidades.

O sujeito é seu próprio projeto, por isso "não há nada de inato ou pré-determinado", as escolhas se dão por meio de uma "estrutura de escolha", onde a situação em que se encontra deliberará certas possibilidades materiais e outras não. Por essa causa, "escolher uma profissão, por exemplo, não é escolher somente um fazer, mas sim um ser, e é exatamente por isso que o sujeito experimenta a angústia" (EHRLICH, CASTRO e SOARES, 2000, p. 75). Até mesmo um homem que vive em condições desumanas, como exemplo um morador de rua, está cercado por possibilidades objetivas para seu ser, segundo o seu contexto. Assim, o ser humano sendo seu próprio plano, vai formando sua personalidade através de suas relações e escolhendo suas possibilidades, cujo futuro o espera para ser definido (EHRLICH, CASTRO e SOARES, 2000).

\section{AS POSSIBILIDADES DA ORIENTAÇÃO PRO- FISSIONAL E DA RE-ORIENTAÇÃO PROFIS- SIONAL}

A Orientação Profissional, criada e constantemente aprimorada desde a crise econômica de 1930 se faz extremamente necessária ao apoio à adaptação das pessoas aos perfis profissionais necessários. Para tanto, novos pressupostos de orientação precisaram ser elaborados, onde o papel do orientador pudesse ser:

Auxiliar o processo de re-adaptação a novas carreiras; buscar a compreensão das relações existentes entre as diferentes ocupações vivenciadas pela pessoa e seus aspectos psicológicos [...]; desenvolver novas capacidades pessoais exigidas pelas novas ocupações como: espírito empreendedor, criatividade, flexibilidade, espírito de equipe, entre outras (LUCCHIARI, 1997, p. 81).

Lucchiari (1997), define a reorientação como facilitadora do processo de adaptação profissional frente às mudanças exigidas pela modernização e pela globalização. O objetivo maior da re-orientação profissional é trabalhar a relação homem-trabalho, a vivência no desemprego da profissão, os sentimentos experimentados e as mudanças exigidas. E permitir ao indivíduo de progredir em suas sucessivas "escolhas" auxiliando-o a ver a relação existente entre as diversas decisões que vai tomando ao longo de sua vida profissional.

Sabe-se que o ser humano, em geral, tem repúdio à mudança e por isso se encontra em tamanho conflito para aceitá-la e acompanhá-la, ainda que tenha extrema necessidade disso. De acordo com Lucchiari (1997), é nesse 
plano que o trabalho de re-orientação profissional se destaca. Sendo possível em diferentes momentos da vida, desde o período universitário até a aposentadoria ou redirecionamento da carreira, é através desse processo que o indivíduo encontra um novo rumo ao qual se adapte.

Esse período, encarado como época de crise para cada sujeito que o enfrenta, pode ser amenizado por meio do trabalho do psicólogo, que o re-orienta propondo "uma integração da identidade vocacional-profissional com a história pessoal e familiar da pessoa" (LUCCHIARI, 1997, p. 87), além de garantir prevenção da saúde mental do mesmo, a partir do momento em que o seu novo trabalho é planejado para ser acima de tudo, uma fonte de prazer.

A demanda por orientação profissional no processo de re-escolha ou re-opção tem sido cada vez maior no cenário atual, o que se esclarece, entre muitos outros fatores, o alto índice de insatisfação, troca e/ou desistência dos cursos superiores, ou ainda quando o estudante quer seguir estudos em uma pós-graduação e aproveita a oportunidade para redefinir sua escoIha anterior. Nas palavras de Hotza \& Lucchiari (1998, apud MOURA e MENEZES, 2004, p. 30), "A insatisfação com a opção realizada ou com a formação profissional conquistada, é corroborada pela crescente demanda de universitários ou ex-universitários por trabalhos de orientação profissional."

Moura e Menezes (2004), salientam que escolher ou re-escolher não é um processo simples, pois traz consigo a tomada de decisão para qual a maioria das pessoas não recebeu um preparo adequado, quer seja pela formação familiar, escolar ou de outras instituições educativas.

Após o período universitário, geralmente, cada indivíduo ocupa determinado segmento profissional, onde pode encontrar-se estabilizado ou não, neste e em diversos outros casos, o mesmo também pode servir-se da orientação ou re-orientação.

Já no período final do percurso laboral, em geral caracterizado pela aposentadoria, pode ser encarado de duas maneiras pelo profissional. Enquanto crise, quando há certa recusa em aceitar a situação ou necessidade de voltar ao trabalho por sobrevivência; e enquanto liberdade, quando é incentivado pela assistência familiar ou pela busca de prazer através do lazer. Nessas situações, os indivíduos podem continuar trabalhando na mesma ocupação ou procurar outra (quando os honorários de aposentados não lhe permitem sustentar-se). Ou fazer projetos de futuro, geralmente ligados à prosperidade, ou seja, aproveitam como um momento especial em suas vidas propício para buscar realizar o que sempre sonharam, mas que por inúmeros motivos não puderam fazer anteriormente. Neste momento da vida, existe a possibilidade de reorientarem-se, pois estão abertos ao futuro. França e Soares (2009) apresentam a aposentadoria como um período de incertezas, apesar das sofisticadas projeções econômicas tão presentes no mundo atual. E que há, sem dúvida, uma carência de estudos e pesquisas diante dessa realidade, pois são desconhecidos e imprevisíveis os comportamentos dos trabaIhadores e das empresas frente ao aumento da expectativa de vida, visto que os aspectos psicológicos, sociais, econômicos e políticos-culturais envolvidos nesta fase de transição são fortemente influentes e não podem ser desconsiderados.

Por ser uma temática ainda nova, a aposentadoria é acompanhada de contradições, observadas tanto naqueles que estão na transição quanto nos vários segmentos da sociedade, e essa falta de preparo pode provocar uma série de conflitos. De um lado, estão aqueles que podem planejar se aposentar com maior tranqüilidade, podendo transformar essa fase em uma oportunidade de balanço, do despertar de novas possibilidades, seguidas por um recomeço ou otimização da vida; por outro lado, a aposentadoria hoje, e especialmente no Brasil não representa necessariamente a saída dos trabalhadores do mercado de trabalho, uma vez que muitos desejam continuar a ter uma atividade remunerada (CAMARANO, 2001, apud FRANÇA e SOARES, 2009, p. 740).

Diante dessa realidade, faz-se extremamente necessário, segundo França (2008, apud FRANÇA e SOARES, 2009), que as organizações ofereçam um sistema que garanta o bem-estar dos trabalhadores mais velhos e dos que estão se aposentando, sem perder de vista o incentivo à motivação e à produtividade das equipes intergeracionais e a responsabilidade social com todos os seus trabalhadores, mesmo com aqueles que estejam deixando as organizações. Identificando aqueles que desejam, precisam e têm condições de continuar no mesmo tipo de trabalho, os que desejam um trabalho diferente ou mesmo que queiram se aposentar definitiva- 
mente, garantindo o apoio essencial a essa fase.

França e Soares (2009), falam sobre a educação ao longo da vida e os programas de preparação a serem empregados nas organizações, a fim de efetivar a transição trabalho-aposentadoria enquanto planejamento para o futuro, os quais devem conter projetos de atualização e desenvolvimento, aplicação de novas metodologias, inserção digital para os trabalhadores mais velhos, quebra dos preconceitos contra o enveIhecimento e integração entre os trabalhadores mais velhos e mais jovens.

O motivo de tamanha preocupação com essa temática e, principalmente, com os trabaIhadores envolvidos nesse processo é o fato de que, nas palavras de França e Soares (2009), a adaptação à aposentadoria depende de diversos fatores. Sob o ponto de vista psicossocial, é fundamental que sejam analisadas as atitudes dos trabalhadores diante das perdas e os ganhos que acompanham essa transição, de forma que os ganhos possam ser reforçados e o impacto das perdas seja contornado por meio do planejamento, este último elaborado a partir do acompanhamento e orientação psicológica.

O PPA facilita o bem-estar dos futuros apo-
sentados, pois enfatiza os aspectos positivos
e oportuniza a reflexão sobre os aspectos
negativos da transição bem como a discus-
são de alternativas para lidar com eles. É
a oportunidade para receber informações e
para a adoção de práticas e estilos de vida
que promovam a saúde. É também o mo-
mento para (re)construir o projeto de vida a
curto, médio e longo prazos, priorizando os
seus interesses e as atitudes que precisa
tomar para realizar seus projetos pessoais
e familiares (FRANÇA e SOARES, 2009, p.
743-744).

O valor da reorientação profissional e da carreira neste período do aposentar-se é inestimável, e tem por público-alvo um dos principais protagonistas na prática da reorientação, o que Soares et al. (2007, apud FRANÇA e SOARES, 2009), deixa claro ao relatar experiências de aposentados que confirmam que a aposentadoria transforma completamente a vida dos sujeitos. Geralmente altera rotinas, hábitos, expectativas e relacionamentos, o que indica ser fundamental a preparação para o enfrentamento dessas mudanças e a reflexão sobre o planejamento pessoal para o futuro.
Soares (2000, apud FRANÇA e SOARES, 2009), afirma ainda que eles muitas vezes procuram uma nova colocação, tanto pela necessidade de complementar os ganhos, quanto a fim de obter nova ocupação para preencher o tempo vago ou até para concretizar um antigo sonho. Sob esta ótica, o trabalho do psicólogo como re-orientador de projetos para o futuro na aposentadoria pode caracterizar-se por auxiliar na desvinculação com a profissão anterior, a fim de buscar uma atividade que atenda às necessidades e facilite ao reorientando a compreensão de seu avanço e suas escolhas sucessivas, auxiliando-o a ver a relação entre as inúmeras decisões que toma ao longo da vida profissional, visando projetar um futuro com qualidade de vida e realizações (SOARES, 2002 apud FRANÇA e SOARES, 2009).

O papel do orientador deve ser o de contribuir com a reflexão sobre o projeto de vida pessoal e profissional, e, a partir de tal reflexão, auxiliar as pessoas a se darem conta de como lidam consigo mesmas e com as relações de trabalho e sociais, para então, se necessário, reestruturar tais relações, de um modo adequado para si mesmo e para a sociedade. É fundamental que, nesse processo, os indivíduos construam pontes" entre o mundo interno e externo e aprendam a lidar com as possibilidades e as limitações presentes em ambos (SOARES et al., 2000 apud FRANÇA e SOARES, 2009, p. 747).

França e Soares (2009) concluem que a aposentadoria também tem chegado para pessoas ainda jovens, que estão em condições de continuar empregadas nas mesmas ou em outras atividades profissionais e neste sentido, "a reorientação pode ajudar a buscar os sonhos adormecidos, a realização de projetos deixados para trás por motivos familiares e profissionais." (SOARES, 2002, apud FRANÇA e SOARES, 2009, p. 747).

Reis (2008), aborda a prática da re-orientação profissional com pessoas portadoras de deficiências motoras em consequência de acidentes, e aponta que o índice de acidentes procedentes de sequelas físicas tem tido um aumento considerável a cada ano, com destaque para Portugal, país onde fora realizada a pesquisa, apresentando idade predominante de vítimas entre 25 e 35 anos, envolvendo acidentes de trabalho e automobilísticos. 
Visando a adaptação do sujeito a um novo modo de vida, outrora desconhecido por ele mesmo,

É indispensável para o processo de orientação vocacional, reforçar as competências dos indivíduos tendo em conta o contexto familiar, as habilitações, as possibilidades profissionais já consideradas, experiências profissionais, crenças, valores, o tipo de personalidade, assim como as pessoas significativas e de suporte associadas ao indivíduo (REIS, 2008, p. 2).

Nota-se a importância do orientador profissional nesse processo, devendo atentar-se às necessidades desse indivíduo, pelo qual perpassa uma sinestesia, pela forma como era, a maneira que está agora e como habituar-se às novas condições. É relevante que a re-orientação preze pelas habilidades motoras que a vítima perdeu e pelos cuidados de uma nova aprendizagem.

A autora supracitada alude que, segundo Ettinger (1997), a deficiência é percebida como uma diferença pelo olhar médico e não como algo negativo. Porém, o público comporta-se perante o deficiente não apenas como um ser diferente, mas delimitando-o por meio de um estigma. Ressalta ainda, que tempos atrás, a admissão laboral de deficientes físicos era mais comum que os deficientes mentais, e que as atitudes sociais deparadas com tais sujeitos é uma variabilidade, considerando a época e o contexto em que ocorrem.

Portanto, o meio é bastante influente no modo como as pessoas deficientes sentem-se menos adequadas do que as outras ditas normais. Daí a importância de ressaltar alguns fatores primordiais no processo de análise de tais sujeitos, os quais, Reis (2008) distingue em: ajustamento, o indivíduo sente dificuldade de ajustar-se aos padrões sociais, inferindo-lhe uma negação própria e tendo como consequência disto, frustração, vergonha e a sensação de inferioridade; barreiras atitudinais, onde o deficiente defronta-se com obstáculos na inserção laboral; generalizações decorrentes da 'etiquetização' de deficiente, visto que o sujeito deve ser identificado pelo seu mérito e não pela sua inépcia física; altura no ciclo de vida no qual o acidente ocorre, quanto mais tardia a alteração, maiores são os empecilhos de instalação e estabilização e, autoconceito, sendo que tais indi- víduos tendem a criar uma imagem negativa de si mesmo, carecendo de uma análise de suas forças e fraquezas, para que modifique sua percepção.

No entanto, o orientador deve observar as vivências antecedentes ao acidente, sejam elas pessoais ou profissionais, cujos laços e significados foram formados pelo indivíduo, e através dessa análise deve buscar habilidades de enfrentamento, para que esse sujeito possa amadurecer e se desenvolver de acordo com as exigências do ambiente. Por isso, o re-desenvolvimento é destacado da seguinte forma: necessidades fisiológicas, em que o deficiente precisa adaptar-se a cadeira de rodas (se esse for o caso), aprender outras maneiras de produção e aprender a cuidar de sua higiene pessoal; necessidades de segurança, a busca por um emprego similar ao anterior, porém que lhe garanta subsídios ao seu novo modo de vida; necessidades de afeto e de pertença; necessidades de estima; necessidades de autoatualização, desenvolvendo o interior e o exterior, aceitando sua situação.

Conforme explicação anterior, para uma nova realidade ser construída, o deficiente perpassa por habilidades que também devem constituir-se, sendo elas: skills de percepção e resposta a transições, o deficiente compreende que sua dificuldade é agora sua normalidade, e a partir disso, há um aumento considerável em sua auto-estima; skills para avaliar, construir e utilizar sistemas de suporte externos, o suporte esperado pelo sujeito ocorre de poucas pessoas; skills para lidar com o estresse emocional e fisiológico; skills para planejar e implementar a mudança.

Vale ressaltar que o processo de transição é constante na vida do sujeito com deficiência motora, essencialmente na construção de sua profissão, principalmente se antes do acidente o mesmo já possuía certa estabilização no setor laboral. Por isso, a readaptação é fundamental nesse ambiente, fazendo-se necessário que o orientador promova um envolvimento desse sujeito com o seu ambiente de trabalho, evidenciando uma reestruturação e um reconhecimento por parte do indivíduo. As amizades também são muito importantes para esse sujeito que se adapta a uma nova realidade, pois fornecem suporte emocional, proporcionando-lhe motivação para trabalhar.

Reis (2008) destaca o papel do profissional de Orientação Vocacional frente a esse 
público-alvo que requer tantos cuidados. Primeiramente, é importante que o orientador deixe de lado qualquer estigma ou percepção negativa sobre o indivíduo, deixando de lado o medo, para que não interfira em sua prática. É de extrema importância observar se há indícios depressivos por parte do sujeito, uma vez que esse sentimento é comum por ter perdido suas habilidades motoras. Assinala também, que o profissional não deve prender-se apenas em aplicações de teorias, mas obter um olhar sensível e empático para com o deficiente, visto que a intervenção positiva começa pelo psicólogo.

O mundo é, notadamente, não uma realidade fixa e menos ainda um ambiente físico particular, mas sim definitivamente um mundo de construções individuais em permanente mudança, ou melhor, um mundo de co-construções sociais. (FURTH, 1998, apud REIS, 2008, p. 15)

Desse modo, é notória a necessidade de adaptar esse indivíduo, vítima de um acidente que lhe privou de habilidades motoras, num novo campo de vida, o qual engloba família, trabalho e comunidade. Considerando seus nuances, é preciso e possível reestruturar a carreira do sujeito a partir do momento em que ele mesmo considere-se efetivo, autosuficiente e capaz de realizar suas atividades, tecendo laços que fortaleçam a si mesmo e a todos que o envolvem.

Vimos que a reorientação pode beneficiar tanto uma pessoa bem-sucedida que deseja trocar ou experimentar uma atividade diferente, mudar de especialidade dentro da mesma profissão, quanto uma pessoa mal sucedida profissionalmente, que muitas vezes culpa as dificuldades encontradas na profissão por seu insucesso, ou ainda aqueles em situação de desemprego que buscam resolver uma questão emergencial nem sempre ligada à procura de uma nova escolha laboral. A modernização também tem trazido a necessidade cada vez mais urgente de adaptação à tecnologia, e por isso atualmente fala-se muito em reorientação nas empresas. O mundo do trabalho, mediatizado de mudanças tecnológicas: a automação, a globalização, o avanço das comunicações e dos transportes, redes de computadores e Internet tem exigido que os trabalhadores das mais diferentes profissões se modernizem. Esta é mais uma possibilidade de reorientação não como falta de orientação ou má escolha profissional, mas principalmente devido às mudanças externas, no meio ambiente (LUCCHIARI, 1997). Há ainda aqueles que pertencem ao grupo de pessoas com transtornos globais do desenvolvimento, dentre eles, os portadores do transtorno do déficit de atenção e hiperatividade (TDAH). Essas pessoas demandam uma atenção especial em relação a sua vida laboral por portarem determinado tipo de transtorno.

O TDAH é um dos transtornos neuropsiquiátricos mais comuns que atingem a infância. É extremamente comprometedor, visto que interfere desde o desempenho escolar até o futuro profissional do indivíduo, além de gerar prejuízos no âmbito familiar e social oriundos da dificuldade de interação e adaptação aos padrões sociais, que por sua vez, desencadeiam baixa autoestima e quadros de ansiedade. As pessoas acometidas pelo TDAH geralmente não apresentam déficit intelectual, porém o desenvolvimento educacional caracteriza-se como instável devido à ineficiência e desorganização com os estudos e tarefas, gerando dificuldade para o aprendizado e memorização.

A escolha profissional é típica do período da adolescência, fase em que as pessoas diagnosticadas com o TDAH enfrentam inúmeros problemas, além dos considerados normais para essa faixa etária. Costa e Barros (2012), apresentam a possibilidade de re-orientação profissional com portadores deste transtorno, que geralmente apresentam um atraso maturacional de 4 a 6 anos em relação aos demais adolescentes. Por isso, esses pacientes se diferenciam ainda mais do grupo, pois tendem à dificuldade de aceitar normas disciplinares, de aprender com as consequências das suas ações, a ter pouco desenvolvidas as competências de aprendizagem social e conceitual, as quais são imprescindíveis para o desenvolvimento e a exploração da carreira na vida adulta. Neste período, o transtorno manifesta-se mais visivelmente no âmbito profissional, onde os adultos têm consequências como o insucesso e a insatisfação no trabalho, além da dificuldade em selecionar uma carreira, se inserir no ensino superior e/ou se manter em um emprego.

Alguns elementos importantes em todo processo de orientação profissional, representam um dos maiores desafios no trabalho com os jovens com TDAH, porém, uma vez alcançados permitem à orientação e re-orientação profissional um caráter terapêutico e profilático mais 
significativo do que o seria para orientandos em outras circunstâncias, adquirindo um significado crucial no caso dos portadores de TDAH:

(a) o respeito ao ritmo próprio do orientando; (b) estar atento para que o adolescente reflita e baseie sua decisão em seus próprios valores e não naqueles impostos pelo sistema econômico, moral, educacional, social, ou qualquer outro que se sobreponha ao do indivíduo; (c) ter sempre claro que a utilização de técnicas ou testes devem funcionar como recurso e não como fim em si; (d) considerar e refletir junto com o orientando que a escoIha, quando feita, é circunstancial ao momento vivido, e não como uma escolha definitiva e imutável, (e) ajudar o orientando a construir uma forma própria de tomar decisões, que possa ser estendida a outras áreas e a outros momentos de sua vida (BARROS, 2004 apud COSTA e BARROS, 2012, p. 247-248).

Por isso, a orientação profissional com esses pacientes visa propiciar um apoio adicional, uma consciência própria mais acurada e a melhora no desempenho do papel profissional. Ao orientador, cabe conhecer as dificuldades advindas de determinados quadros e traçar estratégias adequadas para a resolução da questão profissional de cada indivíduo.

Quanto às características mais comuns dos orientandos com TDAH em relação à essa prática profissional,o comprometimento do sistema atencional pode evidenciar-sede diversas formas e intensidades, como descrito por Costa e Barros (2012, p. 248):

Atrasar ou esquecer o dia da sessão; esquecer as técnicas que ele precisa realizar em casa; dificuldade em sustentar a atenção nas técnicas aplicadas na sessão; perder o "fio da meada" no meio da conversa, mudar de assunto tendo dificuldade de manter um foco, passar de um assunto para outro, sem finalizar as discussões.

A impulsividade representa um dos aspectos do déficit das funções executivas (essenciais para uma decisão consciente) e pode ser outra característica dos portadores deste transtorno, causando um impacto maior nas atitudes exigidas para a tomada de uma decisão profissional. Neste sentido, se encontra a grande dificuldade das pessoas que não contam com uma motivação particular ou uma habilidade ao longo de sua história de vida, que os direcione a um caminho profissional específico.

As autoras afirmam que "é comum as pessoas com TDAH terem grandes chances de fazer uma escolha profissional de forma impulsiva e irrefletida; por conseguinte, é bem provável que eles apareçam no consultório como um caso posterior de re-orientação" (COSTA E BARROS, 2012, p. 249).

A baixa motivação caracteriza outro complicador do processo de orientação profissional com esses sujeitos, visto que apresentam uma busca incessante pela novidade, o que dificulta a eleição de um único caminho a seguir, abandonando as demais possibilidades existentes, o que resulta em uma carga de angústia maior do que nos adolescentes sem o transtorno. "O orientador, sabendo dessa característica, pode apontá-la para o orientando e gerar uma discussão de como ela pode afetar (ou não) a sua escolha profissional e seu desempenho como trabalhador" (COSTA e BARROS, 2012, p. 250).

De acordo com as autoras supracitadas, outro sintoma do TDAH que precisa ser abordado para o trabalho em orientação profissional é a hiperatividade, que ocorre tanto fisicamente quanto mentalmente.

Conhecer e entender o próprio comportamento é fundamental para uma mudança de perspectiva que possibilite um redirecionamento em sua vida. É importante ao TDA aceitar o seu modo de ser e acreditar sinceramente em seus talentos, transformando assim, potencialidades criativas em atos criativos. Ele tem que adquirir confiança para buscar seu espaço nesse novo sistema de trabalho, criatividade, coragem de errar e perseverança de continuar tentando. É necessário que tenha um ideal firme e que creia no seu próprio sonho para torná-lo real (SILVA, 2009, apud COSTA e BARROS, 2012, p. 251).

Para a execução de um trabalho efetivo, é imprescindível que o profissional orientador ou re-orientador profissional conheça o transtorno e trabalhe para adaptar o processo às características desses pacientes, buscando recursos que auxiliem a reflexão e a escolha consciente de um futuro profissional.

\section{CONSIDERAÇÕES FINAIS}

Portanto, diante de tudo o que foi expos- 
to no decorrer do artigo, consideramos de suma importância que seja realizada uma reflexão sobre a atuação do psicólogo enquanto re-orientador profissional que tem embasamento histórico/ teórico acerca de conhecimentos que proporcionem uma prática que alcance possíveis eventos singulares a cada sujeito. Essa prática é possível por meio de estratégias que promovam a qualidade de vida, a partir do conhecimento de si mesmo agregado ao conhecimento técnico das possibilidades profissionais.

Diferente do que é concebido pelo senso comum, a re-orientação profissional transcende o processo de orientação profissional, não no sentido de sobrepor uma à outra, mas na abrangência das situações em que o orientando pode recorrer a esta prática, permitindo que o sujeito se posicione diante das dúvidas relacionadas à escolha profissional.

Ao profissional, cabe ter uma postura imparcial, sem julgamento, proporcionando auxílio e compreendendo o sujeito, de modo que esse reconheça e reflita sobre suas possibilidades de escolhas, ampliando suas percepções a respeito do leque de profissões acessíveis. A prática daquilo que nos apetece, é extremamente saudável em qualquer momento da vida, Soares (1997, apud FRANÇA e SOARES, 2009) mencionava que a situação mais feliz é aquela em que o trabalho e o hobby coincidem, ou seja, aquilo que é trabalho representa uma fonte de prazer.

\section{REFERÊNCIAS}

ABADE, F. L. Orientação Profissional no Brasil: Uma Revisão Histórica da Produção Científica. Revista Brasileira de Orientação Profissional, São Paulo, v. 6, n. 1, p. 15-24, jun. 2005.

COSTA, N. S.; BARROS, D. T. R. Orientação Profissional com Portadores de TDAH: informações e adaptações necessárias.

Revista Brasileira de Orientação

Profissional, Minas Gerais, v. 13, n. 2, p. 245252, jul./dez. 2012.

EHRLICH, I. F.; CASTRO, F.; SOARES, D. H. P. Orientação Profissional: liberdade e determinantes da escolha profissional.

Revista de Ciências Humanas, Florianópolis: EDUFSC, n. 28, p. 61-79, out. 2000.
LASSANCE, M. C.; SPARTA, M. A orientação profissional e as transformações no mundo do trabalho. Rev. Bras. Orientac. Prof., São Paulo, v. 4, n. 1-2, p. 13-19, dez. 2003.

\section{LUCCHIARI, D. H. S. A re-orientação} profissional apoio em época de crise. Rev. ABOP, Porto Alegre, v. 1, n. 1, p. 81-88, jun. 1997.

MELO-SILVA, L. L. Histórico da Associação Brasileira de Orientação Profissional. Revista Brasileira de Orientação Profissional, São Paulo, v. 8, n. 2, p. 1-9, dez. 2007.

MOURA, C. B.; MENEZES, M. V. Mudando de opinião: análise de um grupo de pessoas em condição de re-escolha profissional. Revista Brasileira de Orientação Profissional, São Paulo, v. 5, n. 1, p. 29-45, jun. 2004.

MOURA, C. B.; SILVEIRA, J. M. Orientação Profissional sob o Enfoque da Análise do Comportamento: Avaliação de uma Experiência. Revista Estudos de Psicologia, Campinas, v. 19, n. 1, p. 5-14, jan./abr. 2002.

REIS, M. A. P. A (re)orientação vocacional de pessoas com deficiências motoras em consequência de acidentes. O Portal dos Psicólogos. Porto, jun. 2008.

SOARES, D. H. P.; FRANÇA, L. H. F. P. Preparação para a aposentadoria como parte da educação ao longo da vida. Psicologia: Ciência e Profissão, Brasília, v. 29, n. 4, p. 738-751, 2009.

SPARTA, M. O Desenvolvimento da Orientação Profissional no Brasil. Revista Brasileira de Orientação Profissional, São Paulo, v. 4, n. 1-2, p. 1-11, dez. 2003.

TEIXEIRA, M. O. A abordagem sócio-cognitiva no aconselhamento vocacional: Uma reflexão sobre a evolução dos conceitos e da prática da orientação. Rev. Brasileira de Orientação Profissional, São Paulo, v. 9, n. 2, p. 9-16, dez. 2008. 
FABRIS et al.

\section{LA ORIENTACIÓN A ORIENTACIÓN PROFESIONAL: REFLEXIONES SOBRE EL PAPEL DEL PSICÓLOGO ANTE EL ACTUAL ESCENARIO DE CAMBIOS PROFESIONALES}

RESUMEN: El presente artículo objetiva resaltar aspectos acerca de la actuación del psicólogo como orientador e reorientador profesional, y la amplitud de este proceso, apuntando hacia sus ricos subsidios teóricos y prácticos para el escenario contemporáneo, el cual presenta una vasta demanda de esta práctica en diversas circunstancias atravesadas pelos sujetos. En la búsqueda de un trabajo preventivo e simultáneamente que promueva calidad de vida, presentamos las posibilidades en que se puede servir da reorientación; un breve histórico de esta práctica en Brasil y las principales teorías psicológicas que dan suporte a la orientación profesional. Para atingir los objetivos de esta pesquisa, fue realizada una cautelosa revisión bibliográfica. Con el estudio se pudo concluir que la praxis del psicólogo en la orientación profesional o en la re-orientación profesional requiere conocimientos teórico, metodológico y de las singularidades de cada sujeto (orientando o re-orientando) y del contexto en que los mismos está inseridos.

Palabras-clave: Calidad de vida; Orientación; Posibilidades; Reorientación. 